\title{
Monitoring land use change and its drivers in Delhi, India using multi-temporal satellite data
}

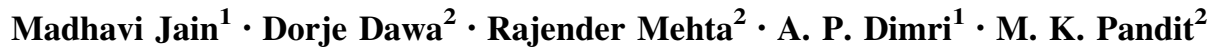

Received: 23 November 2015/Accepted: 9 January 2016/Published online: 22 January 2016

(C) Springer International Publishing Switzerland 2016

\begin{abstract}
Urbanization is the primary driver of Land Use/ Land Cover (LULC) changes throughout the world. It is arguably the most dramatic and prevalent form of irreversible land transformation. In a fast growing city like Delhi, land use changes are tremendous. Therefore, it is imperative to analyze the driving forces of such change. Along with Delhi, the South West District of Delhi has been chosen for a comparative study of LULC change from 1977 to 2014. Landsat and Indian Remote Sensing (IRS) satellite scenes were used to perform both supervised and unsupervised classification and an overall accuracy of over $90 \%$ was achieved for all the years. In Delhi, net percent change from 1977 to 2014 was found to be $+30.61 \%$ for built-up area, $-22.75 \%$ for cultivated area, $-5.31 \%$ for dense forest, $-2.76 \%$ for wasteland and $+2.41 \%$ for $\mathrm{road} /$ rail network. No major net percent change was seen in open forest, scrubs/degraded forest, plantations and river/ waterbody. The LULC results provide evidence of relationship between built-up area, agricultural land and wasteland over the past four decades. The effect of economic reforms of 1991 has manifested itself as a change in LULC. Overall it illustrates a characteristic picture of LULC change and its dynamics.
\end{abstract}

Keywords Land Use/Land Cover (LULC) . Urbanization $\cdot$ Remote sensing $\cdot$ Delhi $\cdot$ Economic reform

A. P. Dimri

apdimri@hotmail.com

1 School of Environmental Sciences, Jawaharlal Nehru University, New Delhi, India

2 Centre for Interdisciplinary Studies of Mountain and Hill Environment (CISMHE), University of Delhi, New Delhi, India

\section{Introduction}

Due to increasing human intervention on the environment, most landscapes on the Earth's surface have been altered in some ways or the other. As a result there is tremendous pressure on the land environment and its components. Land use describes how a parcel of land is used such as agriculture, residences or industry, whereas land cover describes the materials such as vegetation, rocks or buildings that are present on the surface (Lillesand et al. 2003). Land Use/Land Cover (LULC) studies have become key components for managing natural resources and understanding various impacts of human activities on the environment. One of the major causes of LULC change is the rapid pace of urbanization. 'Urbanized societies' in which large proportion of people live in cities developed only in the 19th and 20th century. The growth in the urban to rural ratio is made possible by the movement of people from rural habitats to urban ones or a general progression of the rural area to an urban center because of economic growth and development (Davis 1955).

The world's urban population has multiplied more than ten times in the past century; from 224 million in 1900 to 2.9 billion in 1999 (Alberti 2005). According to United Nations estimates, the population living in urban areas exceeded $50 \%$ of the world total in 2006 and will approach $60 \%$ in 2020. While the world's urban population is expected to increase by almost 2 billion over the next 30 years, the world's rural population is actually expected to decline slightly falling from 3.3 billion in 2003 to 3.2 billion in 2030. Thus, all future population growth for the foreseeable future is expected to be absorbed in urban areas. Most, if not virtually all of this growth, is taking place in the developing countries (Shahraki et al. 2011). 
Urbanization therefore, is arguably an irreversible and in most cases a permanent change that any return to rurality seems unlikely. It is one of the major factors leading to a change in the LULC of a region and has led to the development of a large number of cities (Cohen 2006). Another great factor giving rise to urbanization is the rather late and as yet very incomplete industrialization of agriculture (Davis 1955). According to Davis, as farming becomes highly mechanized and rationalized fewer people are needed on the land. It implies that on an average the more urbanized a country, the lesser is it's rural to urban ratio. The same picture can be seen in today's world.

The present trend of the urbanization in developing countries is especially due to rural-urban migration, the geographic expansion of urban areas through annexations, and the transformation and reclassification of rural villages into small urban settlements. The expansion of the metropolitan periphery is mainly caused both by the arrival of new migrants and by the sub-urbanization of the middle class out of the central city. The relative importance of each of these various causes of urbanization and suburbanization varies both within and between regions and countries. As has been observed in the rest of the world, India had similar impacts of urbanization and LULC change. The independence of the country gave further impetus to the urbanization in Indian cities such as Delhi, Mumbai, Kolkata and Chennai (Delhi Census Handbook 1991). Compared to western urbanization, which followed a gradual shift in economic base from agriculture to industry and then to tertiary sector propelled economic development, the economic development in Indian cities is being triggered by service sector growth. The economic liberalization policy of 1991 opened up Indian economy to the international market, which saw incoming of large share of foreign direct investment (FDI) in metropolitan cities.

Delhi region received maximum share of FDI compared to other regions of the country. Along with this allowance of $100 \%$ FDI in real estate and infrastructure by Indian government has made Delhi susceptible to rapid urban growth (Namperumal et al. 2011). Consequent reduction in agricultural and allied activities has led to reduced output from the primary sector to Delhi's economy. This predominant shift from agriculture to service has created abundant job opportunities attracting people from different states in search of employment. Cultural model of elitism is yet another factor that attracts people to the city.

Further, population has been increasing at an exponential rate in the national capital. Delhi's population has increased from a meager 405,800 in 1901 to a staggering 16,753,200 in 2011 (Census of India 2011), making it one of the largest growing cities in the world. Statistics show that 2.22 million immigrants entered Delhi from 1991 to
2001, which is substantially higher than the 1.64 million who had come in from 1981 to 1991 (Delhi Human Development Report 2006). Delhi, unlike many cities, caters not only to its residents, but to an unusually large number of outsiders as well. The city like many growing urban centers attracts a large inflow of migrants from all over India, especially from Bihar, Haryana, Rajasthan, and Uttar Pradesh. An interesting yet unusual feature of Delhi is the large floating population of millions of visitors every year. These short-term visitors are drawn to the city for a variety of reasons including for work and business, for accessing healthcare, for sightseeing and studying. With such dramatic changes in economic policies, population growth and influx along with development of the national capital, it begs the question of whether these can be seen in concurrence with LULC change or not.

While the ground survey method of data collection is usually the traditional method of monitoring land use and urban growth (Olorunfemi 1983), classic land-cover change detection techniques are based on the comparison of sequential land-cover maps derived from remote sensing (Yang and Lo 2002). As a result of the organization problems and time, ground surveys are not possible to undertake in quick succession; hence they do not yield the needed time series data. Meanwhile, this drawback can be easily resolved with the use of remote sensing data. Therefore, the role of techniques such as remote sensing, aerial photography and image processing becomes important. Remote sensing and image processing have been used to document urban growth and dynamics in hundreds of areas throughout the world over the last decades (Miller and Small 2003; Sudhira et al. 2004; Fox and Vogler 2005; Jat et al. 2008; Zeng et al. 2011; Lasaponara and Lanorte 2012). Timely and accurate information on existing LULC pattern, its distribution and changes over time is a prerequisite for planning, utilization and formulation of policies and programs for making any developmental plan. More often than not in developing countries, government data proves to be insufficient, inaccurate, obsolete or simply non-existent (Rahman et al. 2012; Pandit et al. 2007). In such a case where only a few authentic data sources are available in hand, use of satellite imageries proves to be the best solution. A few satellites providing multi-temporal, multi-spectral and multi-resolution data are Landsat, IRS, Quickbird, MODIS, SPOT and IKONOS etc.

Therefore the present study is focused at preparing a multi-temporal GIS database for LULC change and to assess the spatial and temporal LULC changes in Delhi between 1977 and 2014 using remote sensing and GIS techniques. Primary aim of the study is to quantify the changes in various LULC classes over the period of four decades in the study area and to analyze the driving forces of such change. The following section briefly describes the 
region of the study. Section 3 gives a detailed account of the datasets used and the methodology. The LULC results and their interpretations along with accuracy assessments for all the years of the study are presented in Sect. 4 . Section 5 provides the final conclusions of the study.

\section{Study area}

The study area (Fig. 1) covers an area of $1483 \mathrm{~km}^{2}$, which falls under Delhi Metropolitan city as per Census of India, 1991. Delhi is the national capital of India and is located in the coordinates of $76.84^{\circ} \mathrm{E}, 28.41^{\circ} \mathrm{N}$, by $77.35^{\circ} \mathrm{E}, 28.88^{\circ} \mathrm{N}$. According to Census of India (2011), Delhi is comprised of nine administrative districts-North West, North, North East, East, New Delhi, Central, West, South West and South. Besides Delhi is adjoined by couple of large districts which form an integral part of the National Capital Region (NCR). Some of the large satellite cities adjoining Delhi are Gurgaon, Noida, Faridabad and Ghaziabad. In the larger geographic context Delhi is situated between the Himalayas in the north and Aravalis in the south and the river Yamuna in the eastern part. The elevation of the city ranges between 213 and $290 \mathrm{~m}$. The area is characterized by hot and dry summers and fairly cold winters with summer time high temperatures that can reach $45^{\circ} \mathrm{C}$. Rainfall is dominated by monsoonal weather pattern, with maximum rainfall occurring from June to September.

In addition to Delhi, LULC change detection of South West district of Delhi was studied separately because of the fact that over the last two decades the district has been experiencing tremendous growth in built-up areas including new colonies, roads, metro rails. The South West District of National Capital Territory (NCT) of Delhi is situated in the South West part of Delhi. It is located in the coordinates of $76.84^{\circ} \mathrm{E}, 28.48^{\circ} \mathrm{N}$ by $77.22^{\circ} \mathrm{E}, 28.67^{\circ} \mathrm{N}$. The district occupies an area of approximately $420 \mathrm{sq}$. km. (Census of India 2011). The district is divided into three administrative subdivisions-Delhi Cantonment Sub-Division, Vasant Vihar Sub-Division and Najafgarh Sub-Division.

\section{Methodology}

Data acquisition and digital image interpretation methods comprising image pre-processing, image processing and image post-processing has been detailed in the following subsections. Figure 2 provides a flow chart of the methodology followed.

\section{Data acquisition and image pre-processing}

Satellite imageries of the study area were acquired for four distinct years viz. 1977, 1993, 2006 and 2014 (Table 1) from either Landsat or IRS platforms. Alongside raw satellite data, ancillary data comprising Survey of India toposheet at 1:50,000 scale and Master Plan of Delhi was gathered. Ancillary data helps to provide a basic knowledge of the area of interest and various permanent features like road/rail network, rivers etc. were transferred to prepare a base map. Administrative state boundary map of NCT of Delhi was prepared and brought to UTM projection in zone 43North.

(a)

(b)

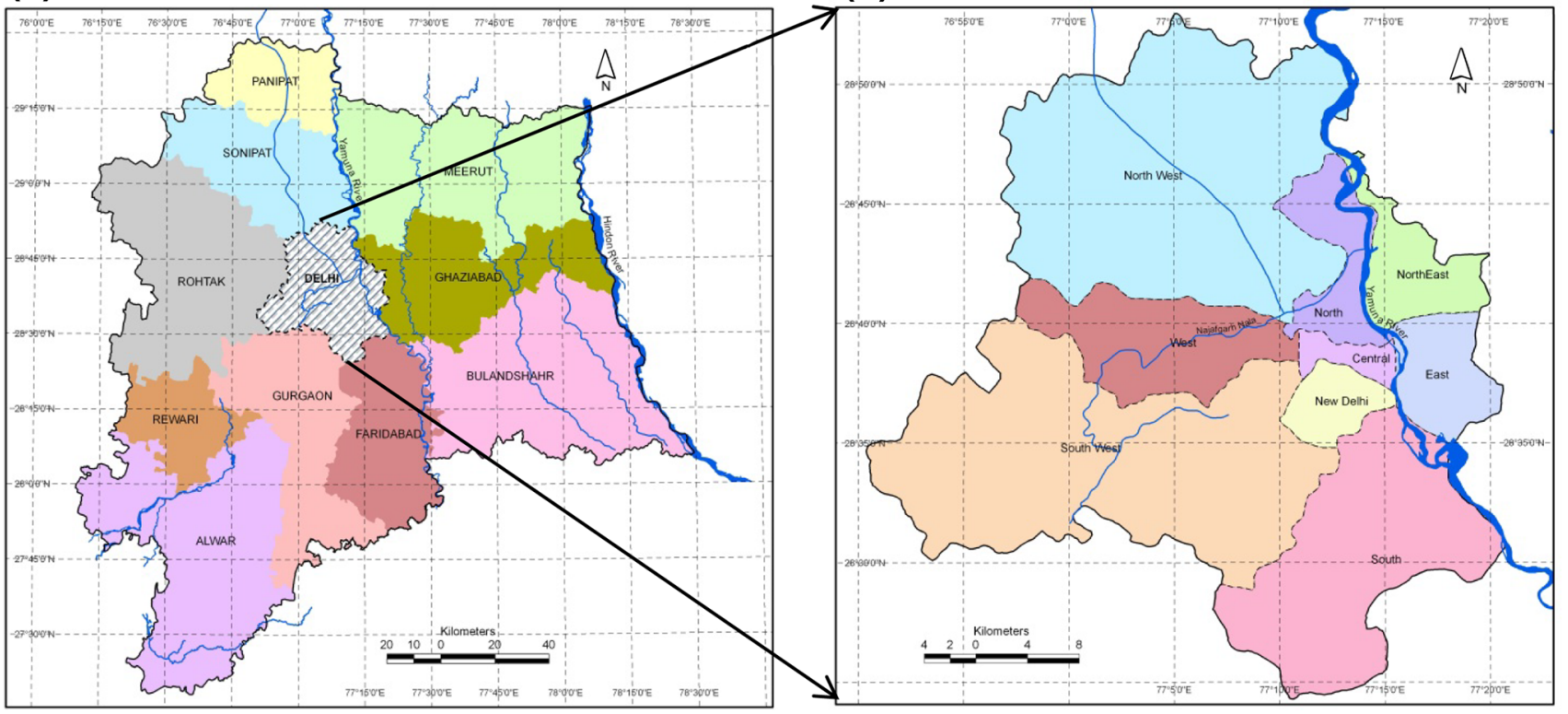

Fig. 1 Maps showing (a) the study area enclosed in NCR region and (b) the nine administrative districts of Delhi 
Fig. 2 Methodology adopted for Land Use/Land Cover map generation

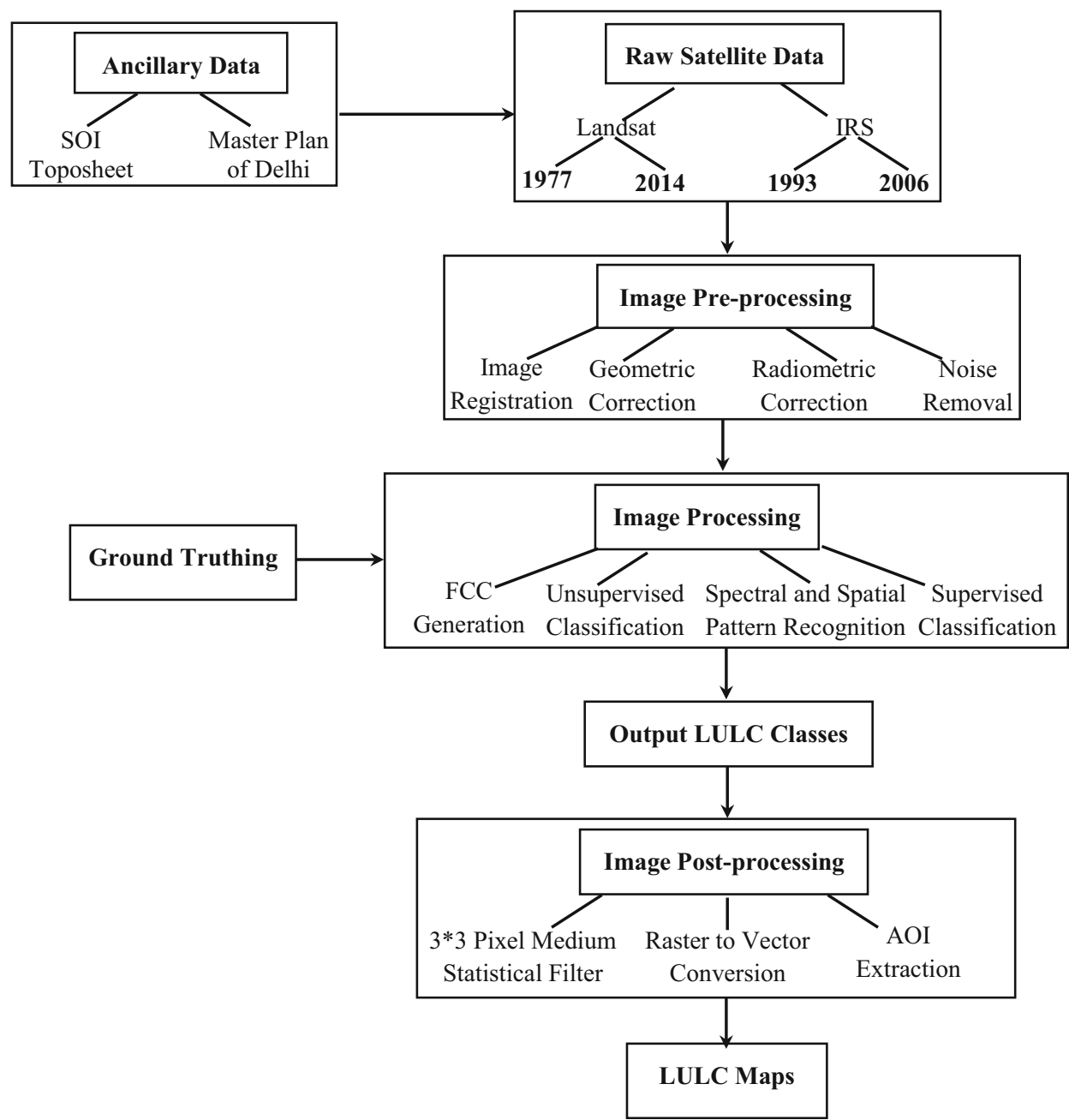

Table 1 Data source

\begin{tabular}{lllll}
\hline Satellite & Sensor & Path/row & Date of acquisition & Data type and bands \\
\hline LANDSAT & OLI & $146 / 40$ & $09-02-2014$ & Digital $(1,2,3,4,5,6,7)$ \\
IRS-P6 & LISS III & $096 / 051$ & $02-01-2006$ & Digital $(2,3,4,5)$ \\
IRS-P3 & LISS III & $029 / 047$ & $05-11-1993$ & Digital $(2,3,4,5)$ \\
LANDSAT & MSS & $157 / 040$ & $08-03-1977$ & Digital $(1,2,3,4)$ \\
\hline
\end{tabular}

The Delhi state boundary and boundary of South West district of Delhi were used later on to extract the area of interest (AOI). Image preprocessing methods included initial processing of raw image data to correct for geometric distortions, to calibrate the data radiometrically, and to eliminate the noise present in the data. Since 1993 image was in polyconic projection it was brought to the same projection as the other imageries i.e. UTM WGS84.

\section{Image processing}

Preparation of thematic maps from digital satellite data of the 4 years were carried out on ERDAS Imagine ver. 9.1 and ArcGIS ver. 9.3. Bands NIR, Red and Green of each of the imageries were used to create the False Color Composite (FCC) maps. Figures 3 and 4 show the FCC's of study area for the years 1977, 1993, 2006 and 2014. Image enhancement techniques of brightness and contrast manipulation were used for better visual interpretation. Unsupervised classification scheme with ten subsequent iterations were performed on all the generated FCC's. Spatial and spectral pattern recognition, which includes use of elements like tone, texture, shape and location of pixel groups in the image were adopted for identification of LULC classes. Nine different Land Use classes were prepared-dense forest, open forest, scrubs/degraded forest, 
(a)

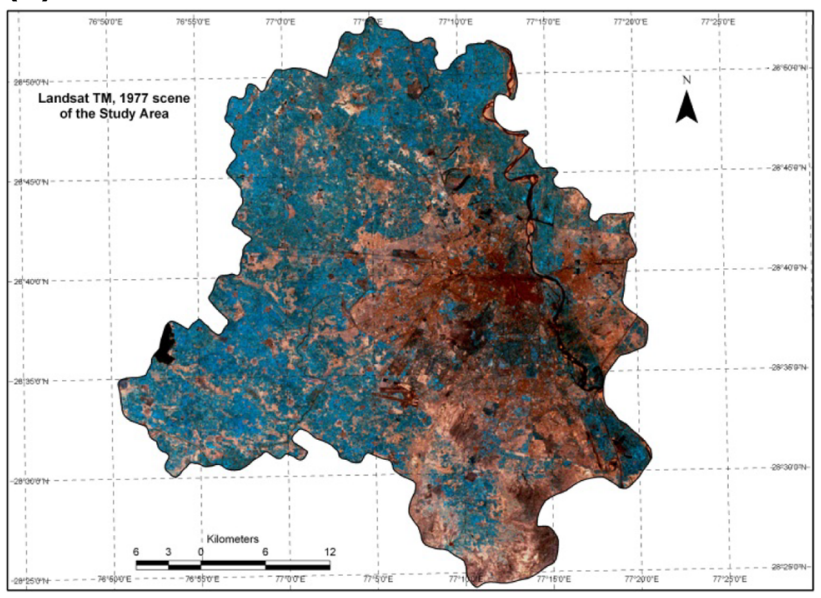

(c)

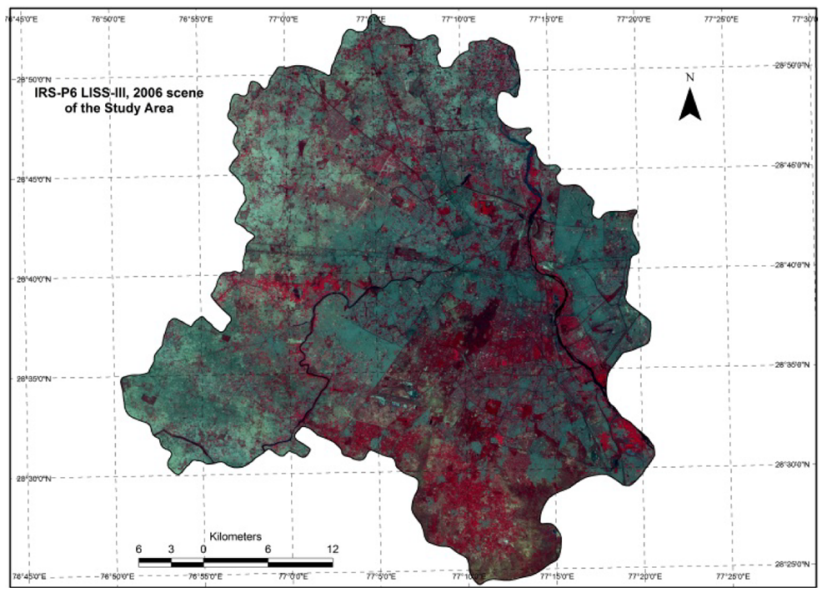

(b)

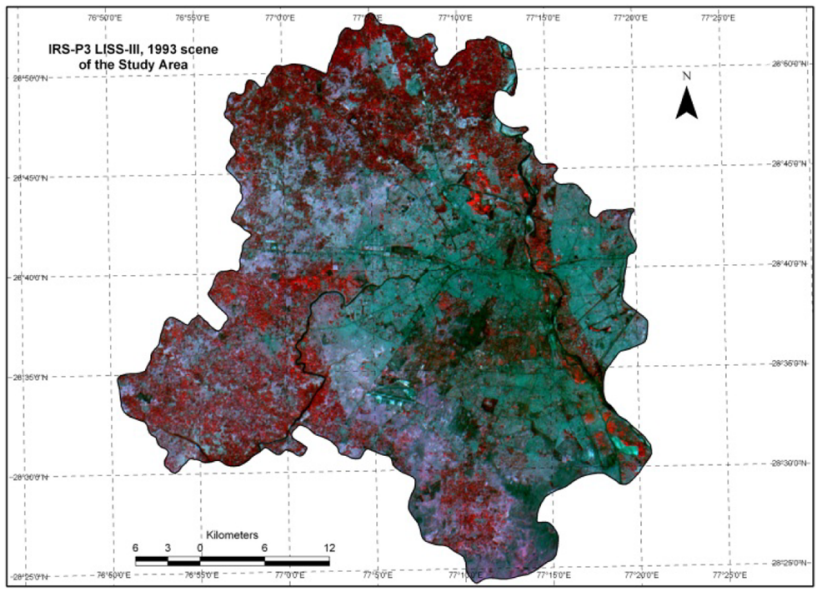

(d)

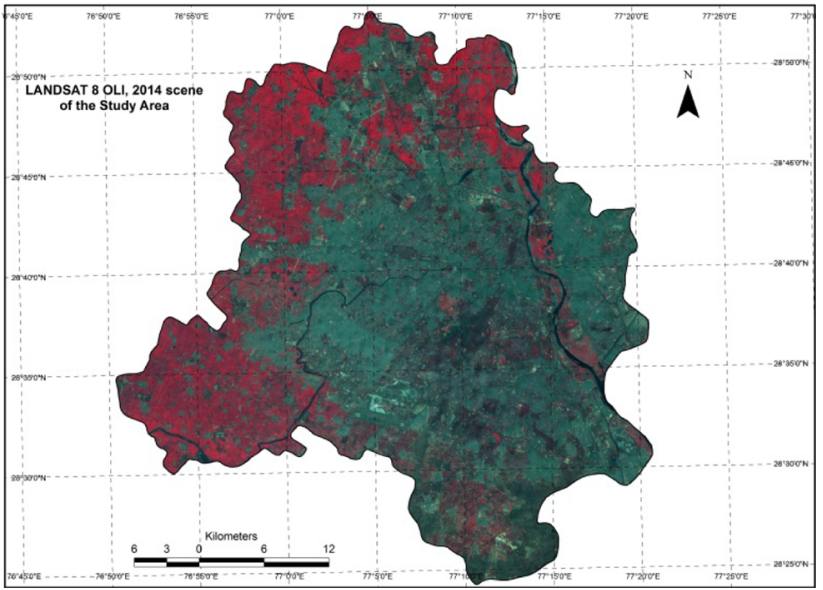

Fig. 3 False color composites of Delhi for the years (a) 1977, (b) 1993, (c) 2006 and (d) 2014

plantations, cultivable area, built-up area, road/rail network, river/waterbody and wasteland. The classification of forest was done on the basis of canopy cover. It is often seen that certain features like dense forest is misinterpreted as water. Therefore for a correct final output these and any other misinterpreted patches amongst all the classes need to be recoded to the correct class. In addition linear features like road/rail network have also been mapped using recoding techniques giving rise to a non-grainy class output. Thus, supervised classification was carried out on the preliminary unsupervised classification output to produce the final LULC output class for the 4 years. This kind of hybrid classification scheme though time consuming produces highly refined and accurate class outputs as compared to either unsupervised or supervised classification alone. Aerial photographs and other photographs were documented as a part of the field survey and ground checking. GPS measurements were taken alongside to validate land use form as seen in photographs with the form as obtained through analysis of satellite imageries.

\section{Image post-processing}

The classified output is smoothed using a $3 * 3$ pixel medium statistical filter to show the majority or the dominant class in the window pass. After carrying out smoothening procedure, the raster LULC outputs are converted to vector formats. In the next step the vector LULC classes are clipped with the AOI boundary and the final LULC map is extracted. Subsequent accuracy assessment was done to check the overall classification accuracy rate. It has been discussed in further detail in the results section. LULC change analysis was carried out for Delhi and South West district of Delhi using the time series output thus generated.

\section{Results and discussion}

In the first sub-section LULC analysis is discussed for Delhi and South West District of Delhi followed by accuracy assessments for each year of classification in 
(a)

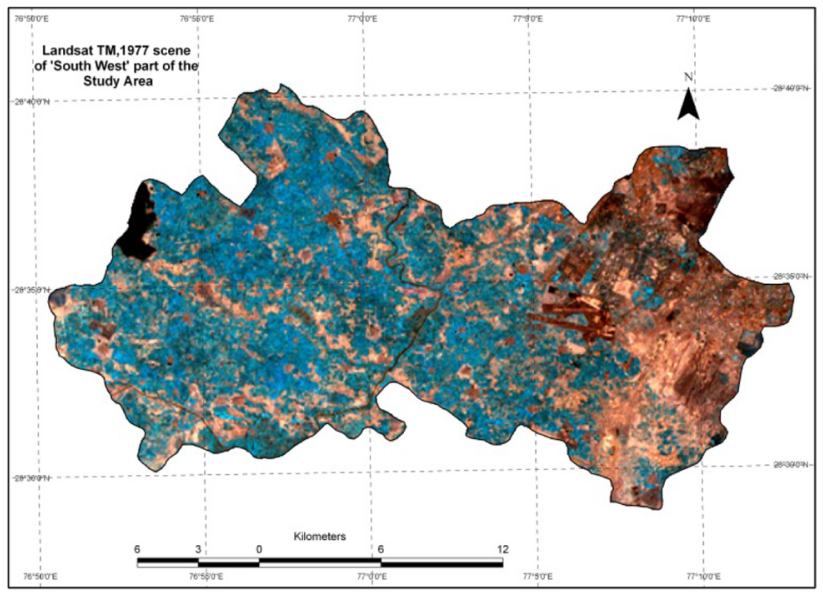

(c)

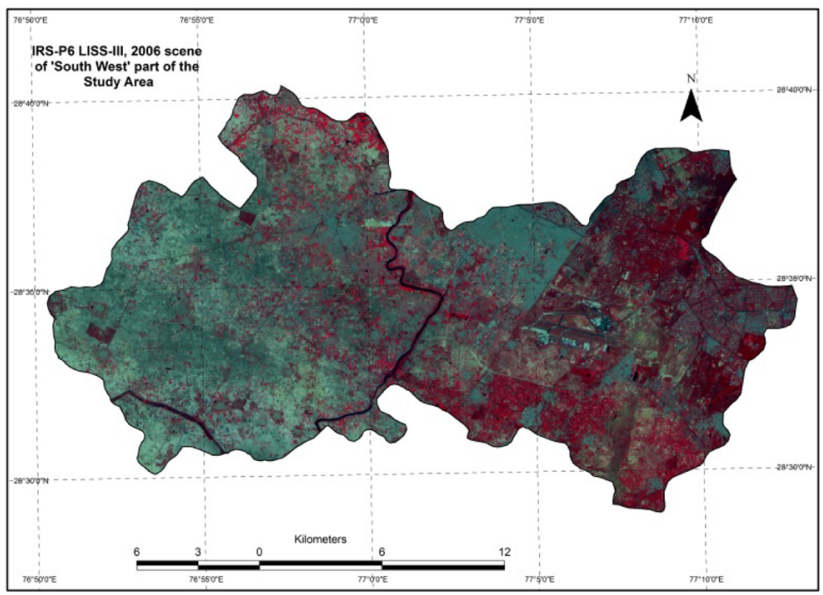

(b)

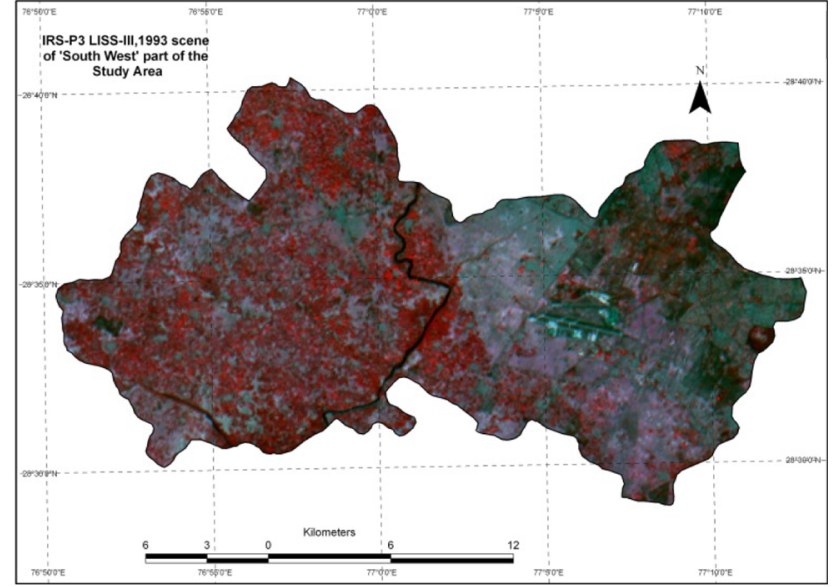

(d)

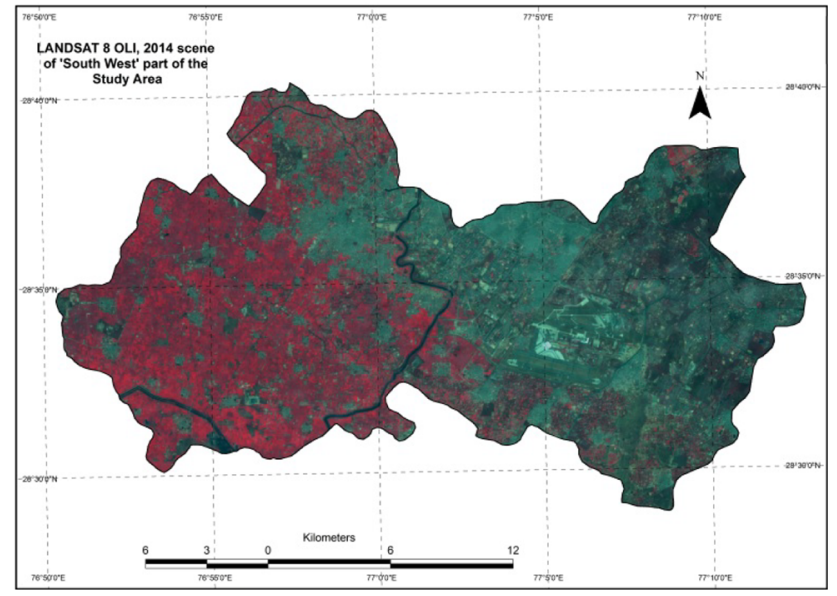

Fig. 4 False color composites of South West District of Delhi for the years (a) 1977, (b) 1993, (c) 2006 and (d) 2014

Sect. 4.2. The net percent change analysis in the nine LULC classes from 1977 to 2014 is provided in Sect. 4.3. The last sub-section discusses the relationships between the LULC classes of built-up area, cultivated area and wasteland in the region of study.

\section{Land Use/Land Cover analysis}

The detailed classified images of Delhi depicting nine different LULC classes for the years 1977, 1993, 2006 and 2014 are shown in Fig. 5. In the span of approximately four decades, enormous changes in LULC pattern can be observed. The city has expanded in terms of built-up area. A radially outward growth from the earliest urban establishments viz. Old Delhi, Mehrauli and Shahdara can be noted over the years. Urban expansion has reached to a situation of near spatial saturation in the trans-Yamuna region, while the relatively new constructed colonies like Dwarka and Rohini are still showing signs of continual growth. Results of LULC change in Delhi are presented in Table 2. Similar study on the South West District of Delhi provided a comparative analysis on the differences in LULC change in a single district in contrast to the whole city. Figure 6 shows LULC maps for the district while the statistics are compiled in Table 3. Several interesting results are presented.

Data interpretation is based on the comparisons between the classes during the span of 38 years. About $40 \%$ of the land in Delhi is presently covered in urban structures. Major increase in built-up area can be attributed to the decades of 1990 and 2000. Mazumdar (2010) states that mid 1990's onwards is the period of rapid economic growth, characterized by private sector driven decisive reinforcement of service sector. This was a direct result of the economic reform policy of 1991. Increasing service sector implies more land for infrastructure along with more residential spaces for the working population. In Delhi it also meant lesser contribution of agricultural sector. 


\section{(a)}

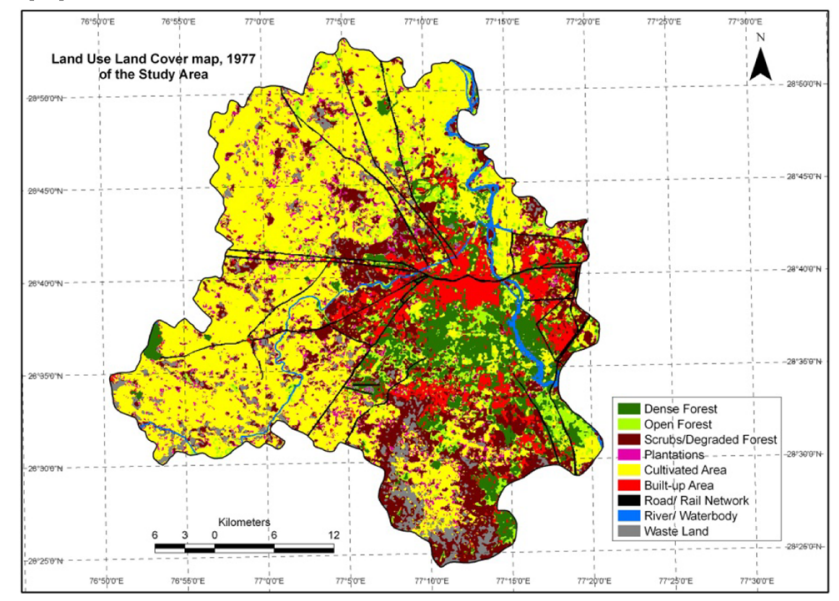

(c)

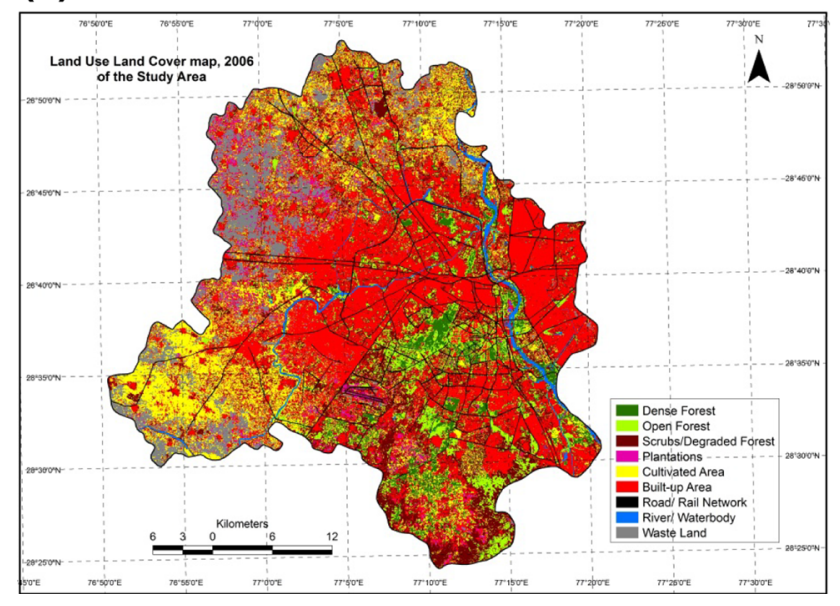

(b)

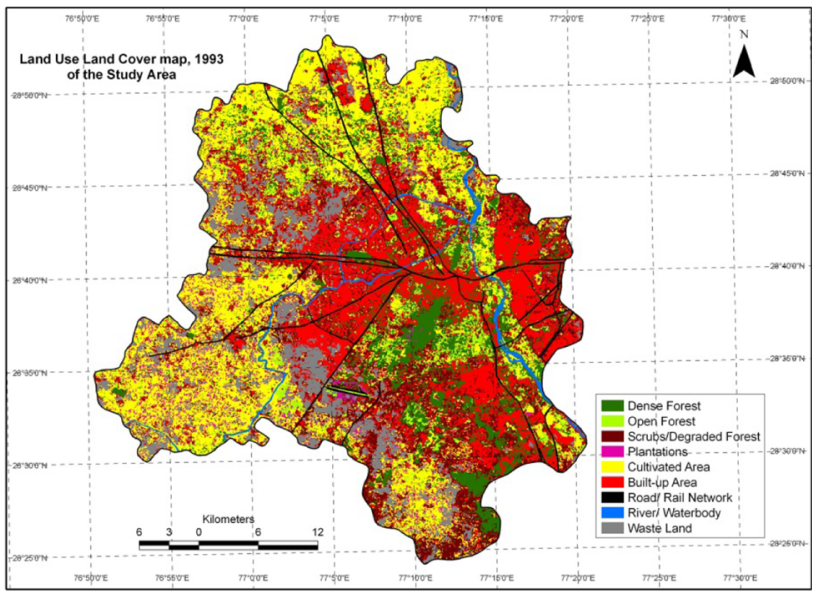

(d)

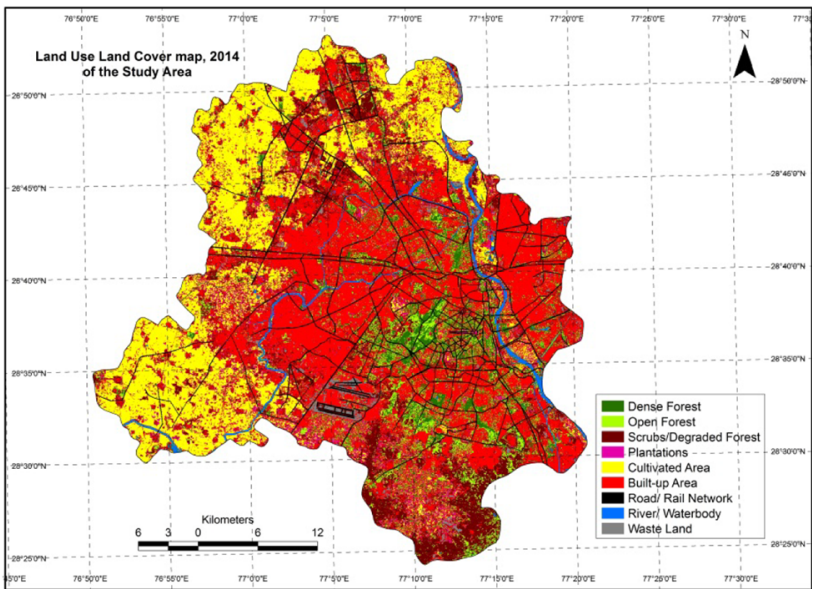

Fig. 5 Land Use/Land Cover distribution over Delhi for the years (a) 1977, (b) 1993, (c) 2006 and (d) 2014

Table 2 Area $\left(\mathrm{km}^{2}\right)$ and percentage of Land Use/Land Cover categories of different years (1977, 1993, 2006 and 2014) of Delhi

\begin{tabular}{|c|c|c|c|c|c|c|c|c|}
\hline \multirow[t]{2}{*}{ Land Use/Land Cover categories } & \multicolumn{2}{|l|}{1977} & \multicolumn{2}{|l|}{1993} & \multicolumn{2}{|l|}{2006} & \multicolumn{2}{|l|}{2014} \\
\hline & Area $\left(\mathrm{km}^{2}\right)$ & $\overline{\text { Area }(\%)}$ & Area $\left(\mathrm{km}^{2}\right)$ & Area $(\%)$ & Area $\left(\mathrm{km}^{2}\right)$ & $\overline{\text { Area }(\%)}$ & Area $\left(\mathrm{km}^{2}\right)$ & $\overline{\text { Area }(\%)}$ \\
\hline Dense forest & 149.84 & 10.10 & 164.83 & 11.11 & 55.49 & 3.74 & 71.10 & 4.79 \\
\hline Open forest & 107.11 & 7.22 & 110.77 & 7.47 & 99.51 & 6.71 & 112.52 & 7.59 \\
\hline Scrubs/degraded forest & 235.74 & 15.90 & 222.52 & 15.00 & 269.61 & 18.18 & 210.58 & 14.20 \\
\hline Plantations & 73.89 & 4.98 & 38.24 & 2.58 & 40.00 & 2.70 & 63.45 & 4.28 \\
\hline Cultivable area & 662.35 & 44.66 & 379.85 & 25.61 & 263.79 & 17.79 & 324.92 & 21.91 \\
\hline Built-up area & 113.77 & 7.67 & 344.99 & 23.26 & 540.49 & 36.44 & 567.64 & 38.28 \\
\hline Road/rail network & 43.42 & 2.93 & 38.72 & 2.61 & 57.18 & 3.86 & 79.17 & 5.34 \\
\hline River/waterbody & 26.69 & 1.80 & 20.36 & 1.37 & 24.61 & 1.66 & 24.38 & 1.64 \\
\hline Waste land & 70.22 & 4.73 & 162.75 & 10.97 & 132.35 & 8.92 & 29.27 & 1.97 \\
\hline Total & 1483.03 & & 1483.03 & & 1483.03 & & 1483.03 & \\
\hline
\end{tabular}

Adding to that the increasing total population pressure, the built-up area is bound to expand. This dramatic change in built-up area in Delhi is concurrent with the economic reform period. Therefore it can be said that changing pattern of economy had a major role in LULC dynamics in the national capital. 
(a)

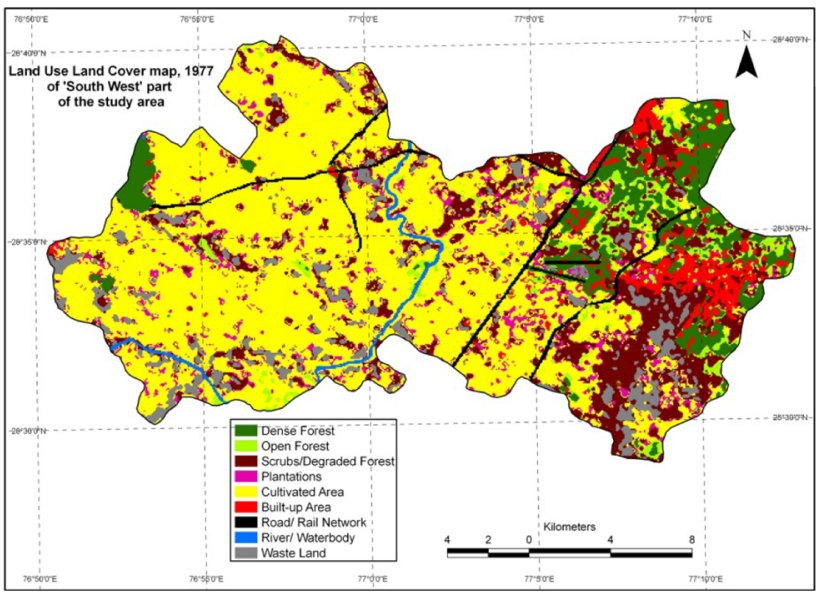

(c)

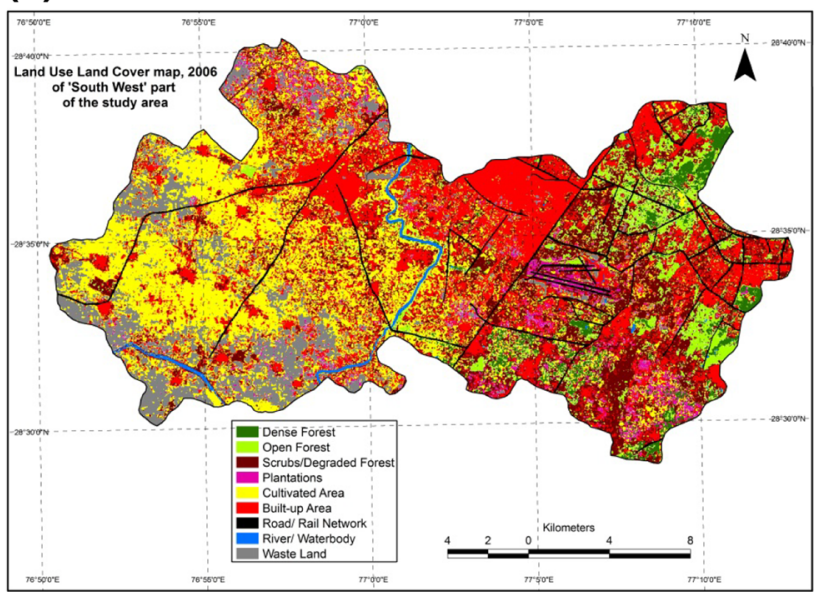

(b)

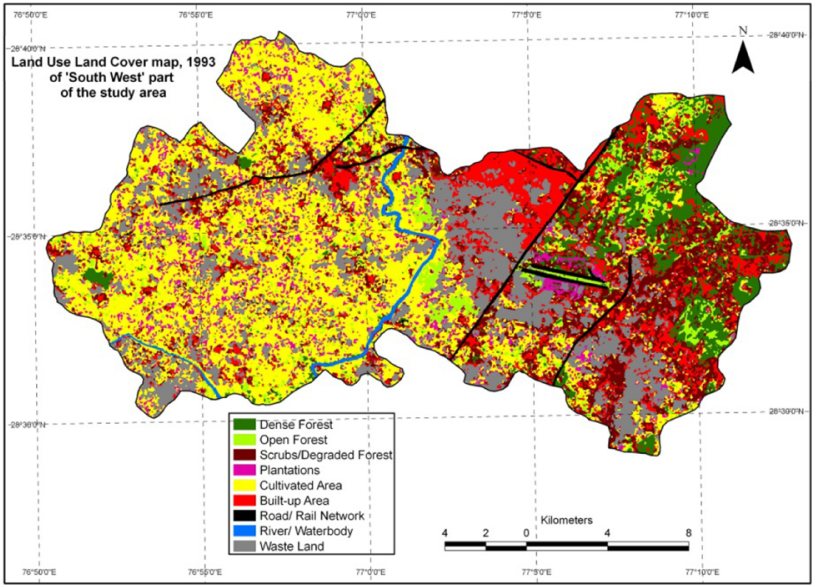

(d)

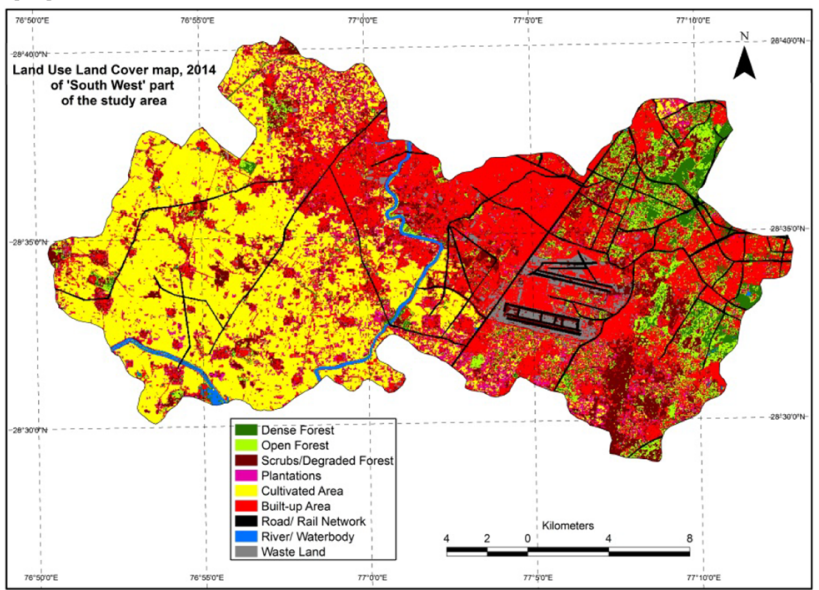

Fig. 6 Land Use/Land Cover distribution over South West District of Delhi for the years (a) 1977, (b) 1993, (c) 2006 and (d) 2014

Table 3 Area $\left(\mathrm{km}^{2}\right)$ and percentage of Land Use/Land Cover categories of different years (1977, 1993, 2006 and 2014) of South West District of Delhi

\begin{tabular}{|c|c|c|c|c|c|c|c|c|}
\hline \multirow[t]{2}{*}{ Land Use/Land Cover categories } & \multicolumn{2}{|l|}{1977} & \multicolumn{2}{|l|}{1993} & \multicolumn{2}{|l|}{2006} & \multicolumn{2}{|l|}{2014} \\
\hline & Area $\left(\mathrm{km}^{2}\right)$ & Area $(\%)$ & Area $\left(\mathrm{km}^{2}\right)$ & Area $(\%)$ & Area $\left(\mathrm{km}^{2}\right)$ & Area $(\%)$ & Area $\left(\mathrm{km}^{2}\right)$ & Area $(\%)$ \\
\hline Dense forest & 32.48 & 7.73 & 31.19 & 7.42 & 19.41 & 4.62 & 17.83 & 4.24 \\
\hline Open forest & 19.32 & 4.60 & 28.66 & 6.82 & 27.13 & 6.46 & 29.36 & 6.99 \\
\hline Scrubs/degraded forest & 58.21 & 13.85 & 58.34 & 13.88 & 60.66 & 14.44 & 49.66 & 11.82 \\
\hline Plantations & 24.43 & 5.81 & 21.78 & 5.18 & 20.96 & 4.99 & 21.82 & 5.19 \\
\hline Cultivable area & 230.24 & 54.79 & 139.71 & 33.25 & 118.14 & 28.11 & 127.96 & 30.45 \\
\hline Built-up area & 17.91 & 4.26 & 56.94 & 13.55 & 115.63 & 27.52 & 132.83 & 31.61 \\
\hline Road/rail network & 8.58 & 2.04 & 7.30 & 1.74 & 14.53 & 3.46 & 20.03 & 4.77 \\
\hline River/waterbody & 4.04 & 0.96 & 3.72 & 0.89 & 3.62 & 0.86 & 4.48 & 1.07 \\
\hline Waste land & 25.01 & 5.95 & 72.58 & 17.27 & 40.14 & 9.55 & 16.25 & 3.87 \\
\hline Total & 420.22 & & 420.22 & & 420.22 & & 420.22 & \\
\hline
\end{tabular}

Between the years 1977-1993 and 1993-2006, the constructed area in Delhi increased 15.59 and $13.18 \%$. The percent increase of built-up area has shown a decline in 2006-2014 reaching to about as low as $1.83 \%$. On the other hand, the South West district shows the constructed area increase being $9.29 \%$ in $1977-1993,13.97 \%$ in 
Table 4 Accuracy assessment of LULC classification over Delhi for the year 1977

\begin{tabular}{lllllllllllll}
\hline & 1 & 2 & 3 & 4 & 5 & 6 & 7 & 8 & 9 & Total & EC & CA \\
\hline 1 & 39 & 2 & 1 & 0 & 0 & 5 & 0 & 3 & 0 & 50 & 0.220 & 0.780 \\
2 & 2 & 46 & 1 & 1 & 0 & 0 & 0 & 0 & 0 & 50 & 0.080 & 0.920 \\
3 & 1 & 1 & 44 & 1 & 0 & 3 & 0 & 0 & 0 & 50 & 0.120 & 0.880 \\
4 & 0 & 0 & 0 & 48 & 2 & 0 & 0 & 0 & 0 & 50 & 0.040 & 0.960 \\
5 & 0 & 3 & 0 & 0 & 46 & 1 & 0 & 0 & 0 & 50 & 0.080 & 0.920 \\
6 & 0 & 0 & 2 & 1 & 0 & 46 & 0 & 0 & 1 & 50 & 0.080 & 0.920 \\
7 & 1 & 0 & 0 & 0 & 1 & 0 & 47 & 1 & 0 & 50 & 0.060 & 0.940 \\
8 & 0 & 1 & 0 & 0 & 0 & 0 & 0 & 49 & 0 & 50 & 0.020 & 0.980 \\
9 & 0 & 0 & 0 & 1 & 3 & 0 & 0 & 0 & 46 & 50 & 0.080 & 0.920 \\
Total & 43 & 53 & 48 & 52 & 52 & 55 & 47 & 53 & 47 & 450 & & \\
EO & 0.093 & 0.132 & 0.083 & 0.077 & 0.115 & 0.164 & 0.000 & 0.075 & 0.021 & & & \\
PA & 0.907 & 0.868 & 0.917 & 0.923 & 0.885 & 0.836 & 1.000 & 0.925 & 0.979 & & &
\end{tabular}

1 dense forest, 2 open forest, 3 scrubs/degraded forest, 4 plantation, 5 cultivable area, 6 built-up area, 7 road/rail network, 8 river/waterbody, 9 wasteland, $E C$ errors of commission, $E O$ errors of omission, $C A$ consumer's accuracy, $P A$ producer's accuracy
1993-2006 and 4.09\% in 2006-2014. It means that in regards to the city, urbanization started rather late in the district and is progressing at a much faster rate. Also, road/ rail network has expanded at a fair rate in both the study areas. Transportation and connectivity certainly gives a boost to the increase in urban areas. Delhi and South West District of Delhi were predominantly agricultural land with as much as 662.35 sq. $\mathrm{km}(44.66 \%)$ and 230.24 sq. $\mathrm{km}$ $(54.79 \%)$ cultivation in the 70 's. Major decline is noted in the 90's in both areas which is concurrent with the changes in Delhi's shift in economy from primary to tertiary sector. Vast hectares of cultivable land could be seen left barren in the imagery of 2006. Cultivation has resumed in some of these parts again, while the others have been converted to built-up area. Overall, the South West District consistently shows about $10 \%$ higher cultivable area in all the 4 years of study. It can be said that agricultural activities dominate more in this district as compared to the city.

Wasteland has shown a varying pattern over the span of time. In Delhi, it increased to more than a double in 1993 from 1977 totaling to about $163 \mathrm{sq}$. $\mathrm{km}$ area. It then declined in 2006 and plummeted to only about $30 \mathrm{sq}$. km area in 2014. In the case of South West district the area under wasteland tripled from 1977 to 1993 and then has declined steadily.

Green cover has decreased in the city in the past four decades. Even after continuous tree plantation drives, sharp decline of $5.31 \%$ in dense forest can be noted. Building of roads cutting through the ridges of Delhi and the recent rampant razing of trees for the construction of metro rail in early 2000's is the major anthropogenic reason accounting the decline. Similar scenario can be observed in the South West District. The LULC class of river/waterbody has remained fairly unchanged in both areas over the years.

\section{Accuracy assessment}

A confusion matrix scheme is used for quantitative accuracy assessment of image classification for all the years. A stratified random sampling method is used to create 50 sample verification points for each of the nine LULC classes following Currit (2005). The verification and original classification pixels are along $\mathrm{x}$-axis and $\mathrm{y}$-axis respectively in the resultant matrix (Tables 4, 5, 6, 7). Errors of omission, errors of commission, consumer's accuracy and producer's accuracy have been calculated for each class. The classified images of 1977, 1993, 2006 and 2014 have an overall classification accuracy of 91.33, 91.33, 91.11 and $91.55 \%$ respectively. On the other hand, the Kappa Index of Agreement (KIA) of the classified images of 1977, 1993, 2006 and 2014 were calculated as $90.25,90.25,90.00$ and $90.50 \%$ respectively. The KIA values which incorporate errors of omission and commission shows slightly lower accuracy level than overall classification accuracy but this level of accuracy is considered to be very good (Guerschman et al. 2003).

\section{Net percent change detection}

Change detection refers to a group of techniques by which significant differences in digital image values in multitemporal images are assessed. From-to algorithm describes LULC classes present before and after a quantitative change in digital image values whereas the other group of algorithms simply detects the presence or absence of change (Currit 2005). Net percent change in LULC classes from 1977 to 2014 for Delhi have been calculated and shown in Fig. 7. Most LULC changes are complex and multidirectional. It may be possible that the net percent 
Table 5 Accuracy assessment of LULC classification over Delhi for the year 1993
Table 6 Accuracy assessment of LULC classification over Delhi for the year 2006

\begin{tabular}{lllllllllllll}
\hline & 1 & 2 & 3 & 4 & 5 & 6 & 7 & 8 & 9 & Total & EC & CA \\
\hline 1 & 42 & 2 & 0 & 1 & 0 & 0 & 0 & 5 & 0 & 50 & 0.160 & 0.840 \\
2 & 1 & 44 & 1 & 1 & 3 & 0 & 0 & 0 & 0 & 50 & 0.120 & 0.880 \\
3 & 0 & 1 & 44 & 1 & 0 & 1 & 3 & 0 & 0 & 50 & 0.120 & 0.880 \\
4 & 0 & 0 & 1 & 47 & 0 & 1 & 0 & 0 & 1 & 50 & 0.060 & 0.940 \\
5 & 0 & 3 & 0 & 1 & 43 & 0 & 1 & 0 & 2 & 50 & 0.140 & 0.860 \\
6 & 0 & 0 & 0 & 1 & 0 & 46 & 3 & 0 & 0 & 50 & 0.080 & 0.920 \\
7 & 0 & 0 & 0 & 0 & 1 & 1 & 48 & 0 & 0 & 50 & 0.040 & 0.960 \\
8 & 0 & 0 & 0 & 0 & 0 & 0 & 0 & 50 & 0 & 50 & 0.000 & 1.000 \\
9 & 0 & 0 & 0 & 0 & 2 & 1 & 0 & 0 & 47 & 50 & 0.060 & 0.940 \\
Total & 43 & 50 & 46 & 52 & 49 & 50 & 55 & 55 & 50 & 450 & & \\
EO & 0.023 & 0.120 & 0.043 & 0.096 & 0.122 & 0.080 & 0.127 & 0.091 & 0.060 & & & \\
PA & 0.977 & 0.880 & 0.957 & 0.904 & 0.878 & 0.920 & 0.873 & 0.909 & 0.940 & & &
\end{tabular}

1 dense forest, 2 open forest, 3 scrubs/degraded forest, 4 plantation, 5 cultivable area, 6 built-up area, 7 road/rail network, 8 river/waterbody, 9 wasteland, $E C$ errors of commission, $E O$ errors of omission, $C A$ consumer's accuracy, $P A$ producer's accuracy

\begin{tabular}{lllllllllllll}
\hline & 1 & 2 & 3 & 4 & 5 & 6 & 7 & 8 & 9 & Total & EC & CA \\
\hline 1 & 49 & 1 & 0 & 0 & 0 & 0 & 0 & 0 & 0 & 50 & 0.020 & 0.980 \\
2 & 2 & 41 & 5 & 0 & 1 & 1 & 0 & 0 & 0 & 50 & 0.180 & 0.820 \\
3 & 0 & 2 & 44 & 3 & 0 & 0 & 0 & 0 & 1 & 50 & 0.120 & 0.880 \\
4 & 0 & 1 & 0 & 44 & 1 & 2 & 1 & 0 & 1 & 50 & 0.120 & 0.880 \\
5 & 1 & 0 & 0 & 3 & 42 & 0 & 0 & 0 & 4 & 50 & 0.160 & 0.840 \\
6 & 0 & 0 & 0 & 2 & 0 & 45 & 2 & 0 & 1 & 50 & 0.100 & 0.900 \\
7 & 0 & 0 & 0 & 0 & 0 & 1 & 49 & 0 & 0 & 50 & 0.020 & 0.980 \\
8 & 1 & 0 & 0 & 0 & 0 & 0 & 0 & 49 & 0 & 50 & 0.020 & 0.980 \\
9 & 0 & 0 & 0 & 0 & 1 & 2 & 0 & 0 & 47 & 50 & 0.060 & 0.940 \\
Total & 53 & 45 & 49 & 52 & 45 & 51 & 52 & 49 & 54 & 450 & & \\
EO & 0.075 & 0.089 & 0.102 & 0.154 & 0.067 & 0.118 & 0.058 & 0.000 & 0.130 & & & \\
PA & 0.925 & 0.911 & 0.898 & 0.846 & 0.933 & 0.882 & 0.942 & 1.000 & 0.870 & & & \\
\hline
\end{tabular}

1 dense forest, 2 open forest, 3 scrubs/degraded forest, 4 plantation, 5 cultivable area, 6 built-up area, 7 road/rail network, 8 river/waterbody, 9 wasteland, $E C$ errors of commission, $E O$ errors of omission, $C A$ consumer's accuracy, $P A$ producer's accuracy change in area of a certain class showed no considerable change temporally, but did so in spatial terms. Plantations is one such class that can decrease in spatial extent in one area and increase in another area, thereby showing no quantitative change. But urban parameters like road/rail network and built-up area donot usually get demolished and simultaneously erected elsewhere. In the bigger picture, it is possible to extract valuable LULC change information from the net percent change.

From Fig. 7, it can be easily noted that built-up area and cultivable area are two classes showing phenomenal net percent change in area. As much as $+30.61 \%$ net percent change in Delhi and $+27.35 \%$ in South West District can be seen in the class of Built-up area. While for Cultivated area the net percent change stands at $-22.75 \%$ for the city and $-24.34 \%$ for the district. Considerable changes can be observed in dense forest, scrubs/degraded forest, road/rail network and wasteland. Net percent change varied between -1.70 and $-5.31 \%$ in case of forested area and in case of Wasteland it amounted to $-2.76 \%$ for Delhi and $-2.08 \%$ for South West District. Road/Rail Network has changed to $+2.41 \%$ in the city and $+2.72 \%$ in the district from 1977 to 2014. The remaining classes show minimal change in terms of net percent area over time.

\section{Relationship between built-up area, cultivable area and wasteland}

From the analysis of LULC data for Delhi as well as South West District of Delhi it could be gathered that there is a 
Table 7 Accuracy assessment of LULC classification over Delhi for the year 2014

\begin{tabular}{lllllllllllll}
\hline & 1 & 2 & 3 & 4 & 5 & 6 & 7 & 8 & 9 & Total & EC & CA \\
\hline 1 & 43 & 4 & 1 & 2 & 0 & 0 & 0 & 0 & 0 & 50 & 0.140 & 0.860 \\
2 & 1 & 46 & 0 & 2 & 1 & 0 & 0 & 0 & 0 & 50 & 0.080 & 0.920 \\
3 & 0 & 0 & 42 & 0 & 0 & 0 & 7 & 1 & 0 & 50 & 0.160 & 0.840 \\
4 & 0 & 4 & 0 & 43 & 1 & 0 & 0 & 2 & 0 & 50 & 0.140 & 0.860 \\
5 & 3 & 0 & 0 & 2 & 45 & 0 & 0 & 0 & 0 & 50 & 0.100 & 0.900 \\
6 & 0 & 0 & 2 & 0 & 0 & 48 & 0 & 0 & 0 & 50 & 0.040 & 0.960 \\
7 & 0 & 0 & 0 & 0 & 0 & 0 & 50 & 0 & 0 & 50 & 0.000 & 1.000 \\
8 & 1 & 0 & 0 & 0 & 0 & 0 & 1 & 48 & 0 & 50 & 0.040 & 0.960 \\
9 & 0 & 0 & 0 & 2 & 0 & 1 & 0 & 0 & 47 & 50 & 0.060 & 0.940 \\
Total & 48 & 54 & 45 & 51 & 47 & 49 & 58 & 51 & 47 & 450 & & \\
EO & 0.104 & 0.148 & 0.067 & 0.157 & 0.043 & 0.020 & 0.138 & 0.059 & 0.000 & & & \\
PA & 0.896 & 0.852 & 0.933 & 0.843 & 0.957 & 0.980 & 0.862 & 0.941 & 1.000 & & & \\
\hline
\end{tabular}

1 dense forest, 2 open forest, 3 scrubs/degraded forest, 4 plantation, 5 cultivable area, 6 built-up area, 7 road/rail network, 8 river/waterbody, 9 wasteland, $E C$ errors of commission, $E O$ errors of omission, $C A$ consumer's accuracy, $P A$ producer's accuracy (a)

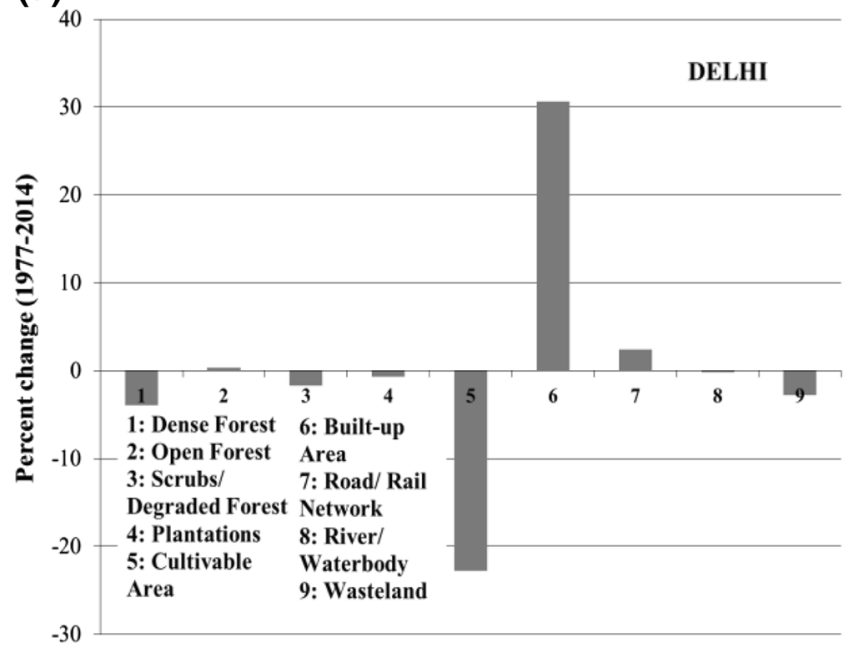

(b)

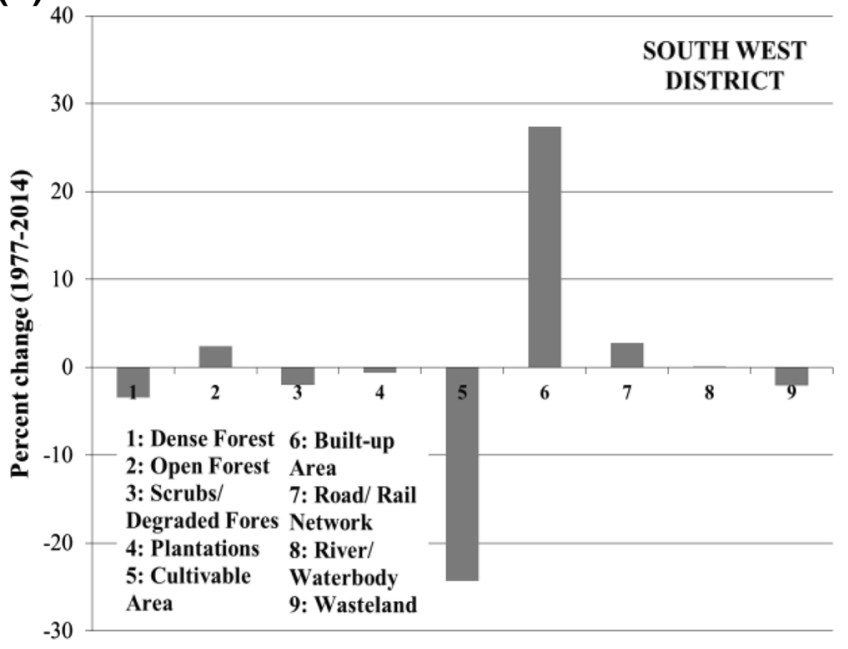

Fig. 7 Net percent change in LULC classes from 1977 to 2014 in (a) Delhi and (b) South West District of Delhi

relationship between the three classes viz. built-up area, cultivable area and wasteland. Delhi's economy has evolved from a predominantly primary sector that was based on agriculture and allied activities to tertiary sector as the opportunities for services and jobs were created. The effect of changing economy has manifested itself as a change in LULC. Table 8 gives the comparative area of the Built-up area and the sum of the other two remaining classes. The relationship between these three LULC classes is depicted through time plots as shown in Fig. 8. In Fig. 8a, b, built-up area, cultivable area and wasteland have been plotted individually over time whereas in Fig. 8c, d, the sum of 'cultivable area and wasteland' along with built- up area has been taken. In the time span of 1977-2014, a general trend of increasing built-up area can be seen in both Delhi as well as South West District of Delhi; the same cannot be inferred for the other two classes. Though if those two classes are combined then the result is far more appreciable. It can clearly be noted from Fig. 8c, d that as the sum of 'cultivated area and wasteland' decreases, the built-up area increases. Practically, no other class has any major impact in the relationship between these three classes. It suffices to say that virtually all urbanization taking place in the city as well as the selected district, is on the land previously occupied by cultivated and wasteland. Land for expansion came from clearing agricultural land 
Table 8 Comparison of Land Use/Land Cover categories of built-up area and sum of cultivable area and wasteland between Delhi and South West District of Delhi for different years (1977, 1993, 2006 and 2014)

\begin{tabular}{|c|c|c|c|c|c|c|c|c|}
\hline \multirow[t]{2}{*}{ Land Use/Land Cover categories } & \multicolumn{4}{|c|}{ Area in Delhi $\left(\mathrm{km}^{2}\right)$} & \multicolumn{4}{|c|}{ Area in South West District $\left(\mathrm{km}^{2}\right)$} \\
\hline & 1977 & 1993 & 2006 & 2014 & 1977 & 1993 & 2006 & 2014 \\
\hline Built-up area & 113.77 & 344.99 & 540.49 & 567.64 & 17.91 & 56.94 & 115.63 & 132.83 \\
\hline Cultivable area + wasteland & 732.57 & 542.60 & 396.14 & 354.19 & 255.25 & 212.29 & 158.28 & 144.21 \\
\hline
\end{tabular}

(a)

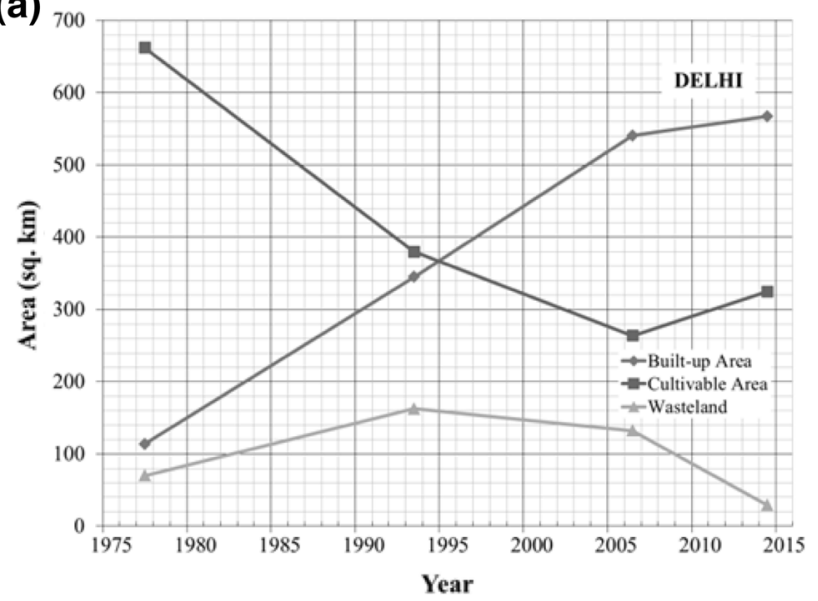

(c)

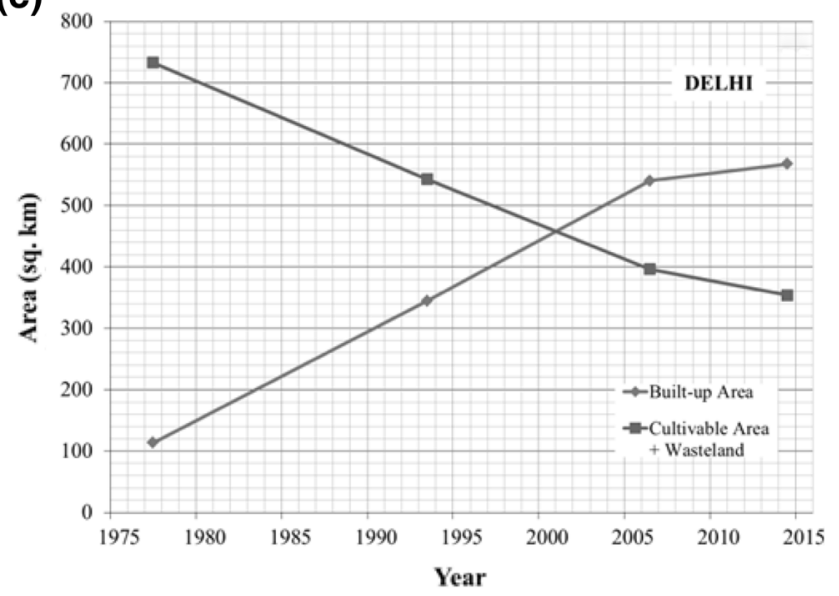

(b)

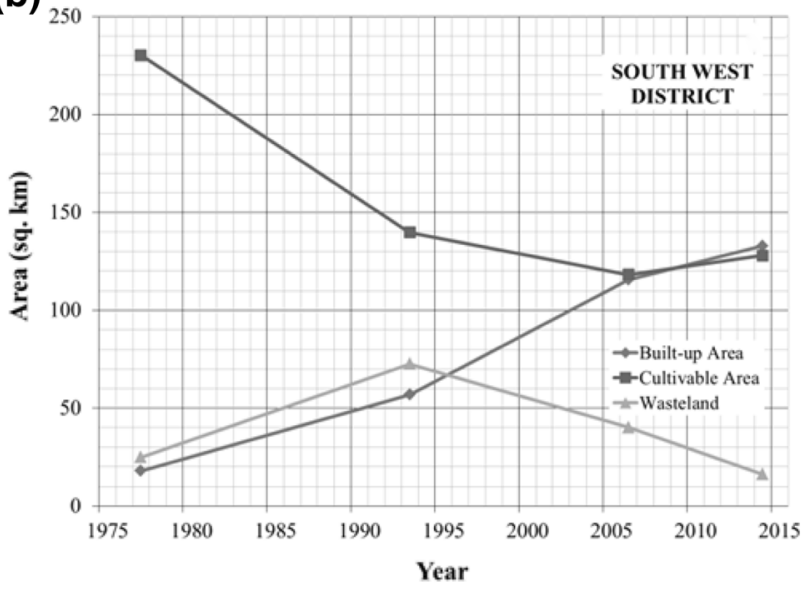

(d)

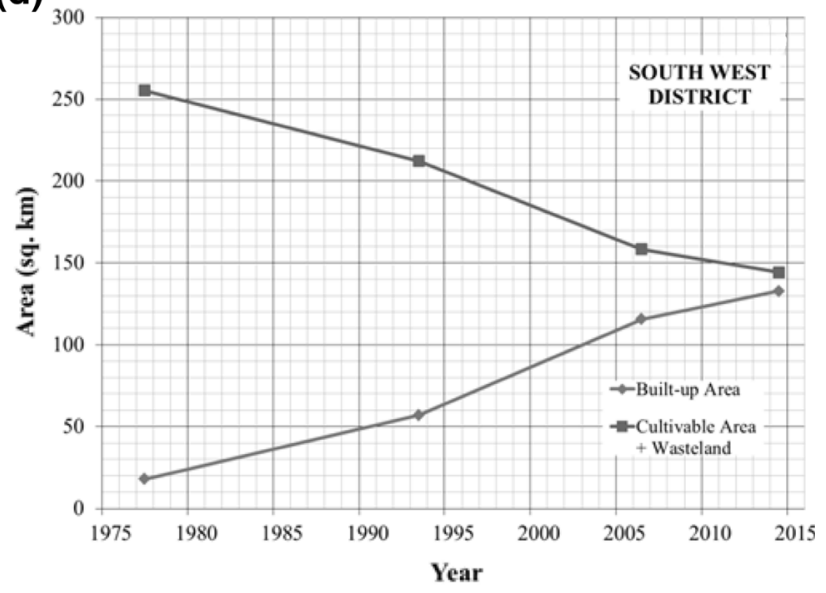

Fig. 8 Time plots depicting relationship between LULC classes for Delhi and South West District of Delhi

which led to increase in wasteland. Therefore, new colonies and existing colonies then sprawled on the empty wasteland. To further strengthen the hypothesis, graphs (Fig. 9) between built-up area and 'cultivated area + wasteland' were drawn. It establishes a near perfect negative correlation between the two variables. The statistical analysis is tabulated in Table 9.

Mann-Kendall test (Kendall 1948) was performed on these variables in cases of Delhi as well as South West district of Delhi. It is a non-parametric test which provides an indication on whether a trend exists and whether it is positive or negative. The ' $\mathrm{S}$ ' statistic indicates whether trend vs. time is generally decreasing (negative $S$ value) or increasing (positive $S$ value). The Confidence Factor (CF) value modifies the $S$ Statistic calculation to indicate the degree of confidence in the trend result, as in 'decreasing' vs. 'probably decreasing' or 'increasing' vs. 'probably increasing'. Additionally, if the confidence factor is quite low, due either to considerable variability or little change in data values vs. time, the CF is used to apply a preliminary 'no trend' classification, pending consideration of the coefficient of variation $(\mathrm{COV})$. The $\mathrm{COV}$ is used to 
(a)

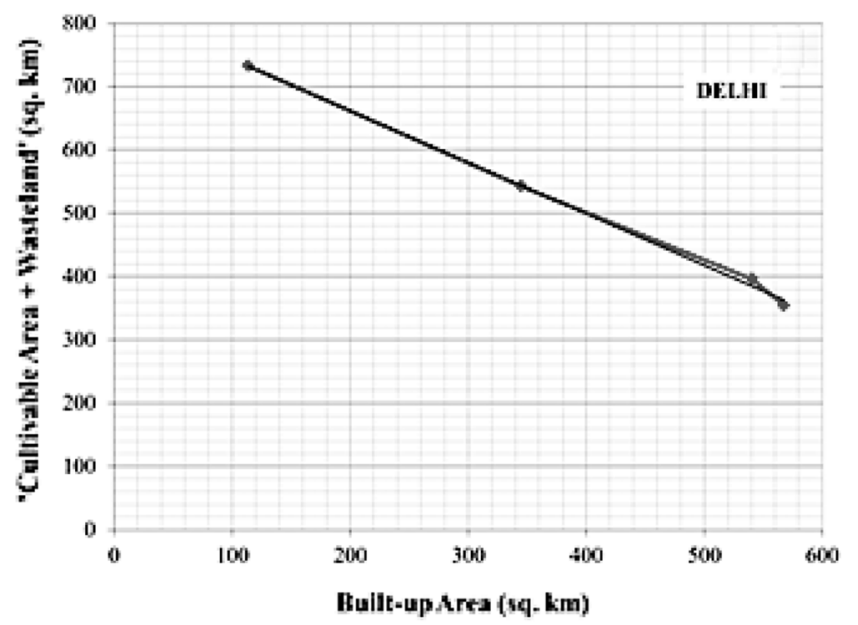

(b)

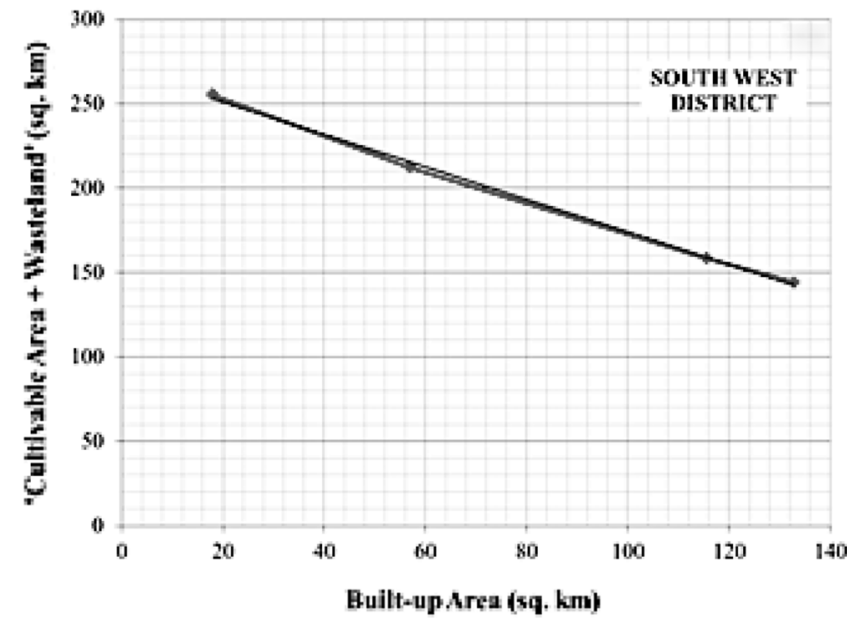

Fig. 9 Correlation between built-up area, and 'cultivable area + wasteland' for (a) Delhi and (b) South West District of Delhi

Table 9 Time plot and correlation statistics between built-up area, cultivable area and wasteland in Delhi and South West District of Delhi

\begin{tabular}{|c|c|c|c|c|}
\hline & \multicolumn{2}{|l|}{ Delhi } & \multicolumn{2}{|l|}{ South West District } \\
\hline & Equation & $\mathrm{R}^{2}$ & Equation & $\mathrm{R}^{2}$ \\
\hline 1. Built-up area ${ }^{a}$ & $y=12.83 x-25246$ & 0.9758 & $y=3.25 x-6410.8$ & 0.9818 \\
\hline 2. Cultivable area + wasteland $^{\mathrm{a}}$ & $y=-10.51 x+21494$ & 0.9872 & $y=-3.14 x+6460$ & 0.9868 \\
\hline Correlation between 1 and $2^{\mathrm{b}}$ & $\mathrm{y}=-0.81 \mathrm{x}+824.84$ & 0.9977 & $y=-0.96 x+270.26$ & 0.9976 \\
\hline
\end{tabular}

${ }^{a}$ Refer to Fig. 8c, d

b Refer to Fig. 9

Table 10 Mann-Kendall statistics between built-up area, cultivable area and wasteland in Delhi and South West District of Delhi

\begin{tabular}{|c|c|c|c|c|}
\hline & \multicolumn{2}{|l|}{ Delhi } & \multicolumn{2}{|c|}{ South West District } \\
\hline & Built-up area & Cultivable area + wasteland & Built-up area & Cultivable area + wasteland \\
\hline Mann-Kendall statistic (S) & 6 & -6 & 6 & -6 \\
\hline Confidence factor (CF) & $95.80 \%$ & $95.80 \%$ & $95.80 \%$ & $95.80 \%$ \\
\hline Coefficient of variation (COF) & 0.54 & 0.34 & 0.66 & 0.27 \\
\hline Concentration trend & Increasing & Decreasing & Increasing & Decreasing \\
\hline
\end{tabular}

distinguish between a 'no trend' result (significant scatter in concentration trend vs. time) and a 'stable' result (limited variability in time) for datasets with no significant increasing or decreasing trend (e.g. low $\mathrm{CF}$ ). Based on the calculations, it was found that built-up area showed an increasing trend $(\mathrm{S}>0, \mathrm{CF}>95 \%)$ and 'Cultivated Area + Wasteland' showed a decreasing trend $(\mathrm{S}<0$, $\mathrm{CF}>95 \%$ ) in both cases (Table 10). Subsequent calculation of Kendall tau value gives the strength of correlation between two data series. Kendall tau is found by dividing the difference of number of concordant and discordant pairs by the total number of possible pairing of $\mathrm{x}$ and $\mathrm{y}$ data values. The value can vary from +1 to -1 , with +1 indicating perfect positive correlation and -1 indicating perfect negative correlation. In both cases of Delhi and South West District of Delhi, the value of Kendall Tau was found to be -1 along with $p$ value being equal to 0.0833 . The results of parametric and non-parametric tests imply with high degree of confidence that there exists a strong negative correlation between the area increasing under built-up land and the area decreasing under cultivable land plus wasteland. Thus it can be said any foreseeable spatial 
urban growth taking place in Delhi will be accounted for by LULC class transformation of the existing cultivable land and wasteland.

Looking closely at Fig. 8a, b it can be noted that the trends of LULC dynamics in South West district of Delhi can be seen following that of the whole state with a lag of about 15 years. Therefore based on evidence of ground reality and from that gathered from the regression analysis, it can be said that the future trend in built-up area and that of 'cultivated area + wasteland' in South West district is more likely to be similar to that already experienced by Delhi in the last decade.

\section{Conclusions}

Thus the study spanning four decades provides an insight to the LULC changes that have taken place in Delhi. The effects of rapid population growth and changing economy have led to unprecedented rates of urbanization thus acting as a driver of LULC change. Increase in built-up area was found to be primarily at the cost of agricultural land and wasteland. A perfect negative correlation was established between built-up area and 'cultivated area + wasteland' based on parametric and non-parametric tests. In addition, it was found that urbanization started later in the South West District but is increasing at a faster rate as compared to Delhi. The Master Plan of Delhi 1962 set out a broad vision for the development of Delhi formulating schemes of large scale acquisition and development of land. Aim of the latter was to ensure the spatial pattern of development and infrastructure and services to match the same (Master Plan for Delhi-2021 2007). But this rapid urbanization has also resulted in increased pollution, decreased water percolation into ground, lesser green cover and urban heat island phenomenon. Rampant spatial urban growth needs to be checked in the future and introduction of vertical stratification through high-rise buildings could possibly be one of the solutions to the city's urban distress. In conclusion satellite remote sensing proved to be a vital tool for continuous observation and quantification of LULC change across varied spatial and temporal scales which otherwise would not have been possible to attempt through conventional mapping techniques.

\section{References}

Alberti M (2005) The effects of urban patterns on ecosystem function. Int Reg Sci Rev 28(2):168-192

Census of India, New Delhi (2011). http://www.censusindia.gov.in. Accessed 5 Feb 2012
Cohen B (2006) Urbanization in developing countries: current trends, future projections, and key challenges for sustainability. Technol Soc 28(1):63-80

Currit N (2005) Development of a remotely sensed, historical landcover change database for rural Chihuahua, Mexico. Int J Appl Earth Obs Geoinf 7(3):232-247

Davis K (1955) The origin and growth of urbanization in the world. Am J Sociol 60(5):429-437

Delhi Census Handbook (1991) Directorate of census operations, Delhi

Delhi Human Development Report (2006). http://planningcommis sion.nic.in/plans/stateplan/sdr_pdf/shdr_del06.pdf. Accessed 24 Apr 2012

Fox J, Vogler JB (2005) Land-use and land-cover change in montane mainland Southeast Asia. Environ Manag 36(3):394-403

Guerschman JP, Paruelo JM, Bella CD, Giallorenzi MC, Pacin F (2003) Land cover classification in the Argentine Pampas using multi-temporal Landsat $\mathrm{TM}$ data. Int $\mathrm{J}$ Remote Sens 24(17):3381-3402

Jat MK, Garg PK, Khare D (2008) Monitoring and modelling of urban sprawl using remote sensing and GIS techniques. Int J Appl Earth Obs Geoinf 10(1):26-43

Kendall MG (1948) Rank correlation methods. Griffin, Oxford, England

Lasaponara R, Lanorte A (2012) Satellite time-series analysis. Int J Remote Sens 33(15):4649-4652

Lillesand TM, Kiefer RW, Chipman JW (2003) Remote sensing and image interpretation. Wiley, New York, pp 1-722

Master Plan for Delhi-2021 (2007) Delhi Development Authority. https://dda.org.in/ddanew/pdf/Planning/reprint\%20mpd2021.pdf. Accessed 26 Apr 2012

Mazumdar S (2010) Industry and services in growth and structural change in India: some unexplored features. MPRA paper no. 20401. http://mpra.ub.uni-muenchen.de/20401/

Miller RB, Small C (2003) Cities from space: potential applications of remote sensing in urban environmental research and policy. Environ Sci Policy 6(2):129-137

Namperumal S, Taubenböck H, Jain M (2011) Seamless urbanisation and knotted city growth: Delhi metropolitan region. In: Proceedings real CORP 2011 Tagungsband, 18-20 May 2011. ISBN: 978-3-9503110-1-3

Olorunfemi JF (1983) Monitoring urban land use in developing countries-an aerial photographic approach. Environ Int 9(1):27-32

Pandit MK, Sodhi NS, Koh LP, Bhaskar A, Brook BW (2007) Unreported yet massive deforestation driving loss of endemic biodiversity in Indian Himalaya. Biodivers Conserv 16(1): $153-163$

Rahman A, Kumar S, Fazal S, Siddiqui MA (2012) Assessment of land use/land cover change in the North-West District of Delhi using remote sensing and GIS techniques. J Indian Soc Remote Sens 40(4):689-697

Shahraki SZ, Sauri D, Serra P, Modugno S, Seifolddini F, Pourahmad A (2011) Urban sprawl pattern and land-use change detection in Yazd. Iran. Habitat International 35(4):521-528

Sudhira HS, Ramachandra TV, Jagadish KS (2004) Urban sprawl: metrics, dynamics and modelling using GIS. Int J Appl Earth Obs Geoinf 5(1):29-39

Yang X, Lo CP (2002) Using a time series of satellite imagery to detect land use and land cover changes in the Atlanta, Georgia metropolitan area. Int J Remote Sens 23(9):1775-1798

Zeng C, Zhou Y, Wang S, Yan F, Zhao Q (2011) Population spatialization in China based on night-time imagery and land use data. Int J Remote Sens 32(24):9599-9620 